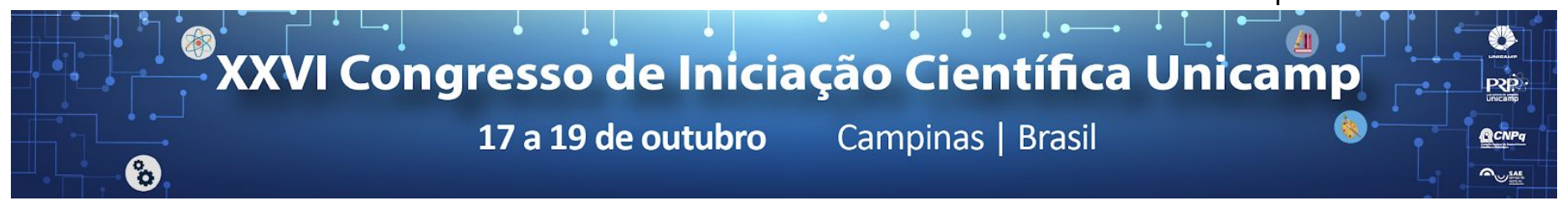

\title{
CARACTERIZAÇÃO FíSICO-QUÍMICA E QUANTIFICAÇÃO DE AMIDO EM REQUEIJÃO CREMOSO
}

\section{Caroline B. Karaziack, Isabelle G. Degaspari*, Walkiria H. Viotto}

\section{Resumo}

Este trabalho teve como objetivo caracterizar dez amostras comerciais de requeijão culinário com adição de amido, comercializados na cidade de Campinas, SP, quanto às características físico-químicas, textura e aceitação sensorial. os resultados obtidos nas análises físico-químicas e de firmeza mostraram grande variação para todos os atributos analisados. No teste de aceitação realizado com 120 provadores, todas as amostras (com e sem amido) tiveram avaliação positiva, mas os provadores mostraram preferir o requeijão sem amido. Os resultados evidenciam falta de padronização entre os requeijões culinários presentes no mercado e que o uso de amido em requeijão é aceito sensorialmente pelos consumidores.

\section{Palavras-chave:}

Requeijão cremoso, amido, aceitação sensorial.

\section{Introdução}

O requeijão cremoso é o segundo queijo mais consumido no Brasil, devido ao uso como ingrediente culinário. Para isso, deve apresentar textura firme e baixa capacidade de derretimento quando submetido a aquecimento. A adição de amido ao produto reduz custos e contribui nas propriedades funcionais desejadas, como a textura. O objetivo deste estudo foi caracterizar 10 amostras de diferentes marcas de requeijão culinário com adição de amido, comercializados na cidade de Campinas, SP, quanto às características físico-químicas, textura e aceitação sensorial.

\section{Resultados e Discussão}

Houve grande variação para todos os atributos analisados, como apresentado na tabela 1. Metade das amostras apresentaram teor de umidade superior ao permitido pela legislação para requeijão cremoso $(65 \%)$. Todos os requeijões apresentaram GBS* > $55 \%$, estando de acordo com a legislação brasileira. A concentração de amido variou de $2,5 \%$ a $8 \%$. Para o requeijão cremoso, não há restrições em relação à adição de amido; apenas que seja declarado a adição de amido no rótulo do produto.

A aceitação sensorial foi realizada com 3 amostras comerciais representativas do lote (diferentes teores de amido), e uma amostra controle (sem adição de amido). Todas as amostras obtiveram notas acima de 5 pontos na escala hedônica, o que caracteriza uma aceitação positiva. Entretanto, os consumidores mostraram preferir o requeijão sem amido.
Tabela 1. Caracterização Fisico-Química de 10 amostras comerciais de Requeijão.

\begin{tabular}{cccccc}
\hline Amostra & $\begin{array}{c}\text { Umidade } \\
(\%)\end{array}$ & $\begin{array}{c}\text { Gordura } \\
(\%)\end{array}$ & $\begin{array}{c}\text { GBS } \\
(\%)\end{array}$ & $\begin{array}{c}\text { Amido } \\
(\%)\end{array}$ & $\begin{array}{c}\text { Firmeza } \\
(\mathrm{N})\end{array}$ \\
\hline 1 & $62,7 \pm 0,1$ & $26,9 \pm 0,3$ & 72,1 & $04,8 \pm 0,1$ & $8,9 \pm 0,4$ \\
2 & $65,1 \pm 0,2$ & $17,2 \pm 0,1$ & 49,2 & $04,3 \pm 0,2$ & $1,8 \pm 0,1$ \\
3 & $62,4 \pm 0,2$ & $24,8 \pm 0,6$ & 65,9 & $02,5 \pm 0,1$ & $4,6 \pm 0,4$ \\
4 & $77,5 \pm 0,1$ & $0,91 \pm 0,1$ & 40,3 & $03,1 \pm 0,4$ & $4,1 \pm 0,2$ \\
5 & $65,4 \pm 0,1$ & $23,8 \pm 0,5$ & 68,6 & $05,5 \pm 0,3$ & $8,2 \pm 1,6$ \\
6 & $78,5 \pm 0,1$ & $0,82 \pm 0,1$ & 38,1 & $08,2 \pm 0,3$ & $3,5 \pm 0,1$ \\
7 & $64,8 \pm 0,1$ & $24,9 \pm 0,7$ & 71,0 & $04,3 \pm 0,1$ & $9,3 \pm 0,8$ \\
8 & $65,2 \pm 0,1$ & $24,6 \pm 0,4$ & 70,8 & $0,5,2 \pm 0,2$ & $1,0 \pm 0,1$ \\
9 & $62,5 \pm 0,1$ & $26,3 \pm 0,5$ & 70,2 & $04,9 \pm 0,1$ & $0,9 \pm 0,1$ \\
10 & $65,2 \pm 0,1$ & $24,6 \pm 0,4$ & 70,8 & $05,2 \pm 0,2$ & $0,9 \pm 0,1$ \\
\hline \multicolumn{5}{c}{ Conclusões } & de
\end{tabular}

padronização entre os requeijões culinários presentes no mercado e que o uso de amido em requeijão é aceito sensorialmente pelos consumidores.

\section{Agradecimentos}

Agradecimento: à CAPES (Coordenação de Aperfeiçoamento de Pessoal de Nível Superior e CNPq (Conselho Nacional de Desenvolvimento Científico e Tecnológico) pelo suporte financeiro (bolsas).

BLIGH, E.G.; DYER, W. J. A rapid method of total lipid extraction and purification. Canadian Journal of Biochemistry and Physiology, Ottawa, v.37, p.911917, 1959.

AOAC. 2006. Official methods of analysis. 18th ed. Association of Official Analytical Chemists, Arlington, Va., U.S.A.

RAPACCI, M. Estudo comparativo das características físicas e químicas, reológicas e sensoriais do requeijão cremoso obtido por fermentação láctica e acidificação direta. Campinas, 1997. 144p. Tese (Doutor em Tecnologia de Alimentos) - Faculdade de Engenharia de Alimentos, Universidade Estadual de Campinas.

AOAC - ASSOCIATION OF OFFICIAL ANALYTICAL CHEMISTS. Official methods of analysis of AOAC International. Starch (Total) in Cereal Products. 996.11. AOAC International, 2000. 